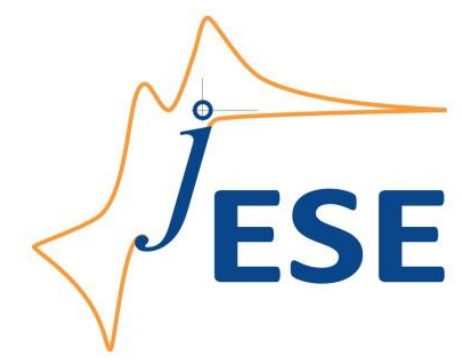

Open Access : : ISSN 1847-9286

www.jESE-online.org

Original scientific paper

\title{
Ruthenium redox equilibria \\ 2. Thermodynamic analysis of disproportionation and comproportionation conditions
}

\author{
Igor Povar $\bowtie$, Oxana Spinu
}

Institute of Chemistry of the Academy of Sciences of Moldova, 3 Academiei str., MD 2028, Chisinau, Moldova

${ }^{凶}$ Corresponding Author: ipovar@yahoo.ca; Tel.: +373 227397 36; Fax: +373 22739736

Received: September 30, 2015; Accepted: February 18, 2016

\begin{abstract}
The key property of Frost diagram has been confirmed using thermodynamic and linear algebra methods. On the basis of the thermodynamic data, the areas of thermodynamic stability of ruthenium species of different valence states as a function of $\mathrm{pH}$ for each degree of oxidation have been determined. Subsequently, based on the diagrams calculated for several values of $\mathrm{pH}$, a narrow $\Delta \mathrm{pH}$ value is determined, in which the dismutation of appropriate form takes place. Based on thermodynamic analysis, the exact value of the beginning of disproportionation (or comproportionation) is found. Finally, the developed revised Frost diagrams of ruthenium heterogeneous chemical and redox equilibria, as a function of $\mathrm{pH}$ and the total concentration of metal ion in solution, have been built.
\end{abstract}

\section{Keywords}

Disproportionation and comproportionation equilibria; Revised Frost diagram; Reduced Gibbs energy of half reaction of oxidation; Ruthenium soluble and insoluble species.

\section{Introduction}

Predicting redox reactions is not necessarily a simple task. It involves a careful examination of the reaction experimental conditionsIn particular, the influence of a number of such factors, as the medium acidity, the complexation and precipitation processes of the redox species is necessary to examine. Predicting redox reactions with the aid of graphical means involves the knowledge of the predominance areas of the redox couples that participate in the equilibria. The superimposition of 
the predominance areas of the two different redox couples permits us to predict the evolution of the global redox reaction qualitatively.

The Frost diagrams (FD) are used to represent the disproportionation conditions of ions and allow judging the possibility along with the extent of disproportionation (comproportionation) of the valence states of the element. In this diagram, there is represented the dependence of the reduced standard energy of formation of ions $\Delta \tilde{G}_{f}^{0}(i)=\Delta G_{f}^{0}(i) / F$ (where $F$ is the Faraday constant equal to $96485 \mathrm{C} \mathrm{mol}-1)$ on the degree of oxidation of an element $(n)$ [1]. So, the Gibbs energy change is expressed in $\mathrm{eV} / \mathrm{mol}$. FD, being simple to accomplish, characterizes clearly the disproportionation (dismutation) processes of ions in solution. The disproportionation occurs if the value $\Delta \tilde{G}_{f}^{0}(i)$ of the analyzed ion is situated above the straight line joining the points $\Delta \tilde{G}_{f}^{0}(i)$ of neighboring valence forms on the $\Delta \tilde{G}_{f}^{0}(i)=f(n)$ diagram. In the case of oxygen-containing species (ions, molecules), on the ordinate axis the standard Gibbs free energy of formation of species ( $\Delta \tilde{G}_{f}^{0}(i)$ ) minus the Gibbs energy of a number $x$ of water molecules, equal to the number of oxygen atoms in the examined species $\left(\Delta \tilde{G}_{f}^{0}(i)=\Delta G_{f}^{0}-x \Delta G_{f}^{0}\left(H_{2} O\right)\right)$, is placed. When the valence form contains more than one element, which is subject to redox transformations, the $\Delta G_{f}^{0^{*}}$ values is calculated per one atom. The standard redox potential represents the negative slope of the straight line joining two points on the diagram, corresponding to any two valence forms, since the equality is valid: $E^{0}=-\Delta G_{f}^{0^{*}} / n$ Here the $n$ quantity coincides with the degree of oxidation of the ion of interest. The angle of inclination of the curve for the given pair of the valence forms characterizes the ability of interaction with the formation of the products with a lower Gibbs energy. By means of this diagram it is easy to establish whether a particular ion is stable against disproportionation. Therefore, the Frost diagram is a convenient source of understanding complex redox chemistry of any element in its various oxidation states and sometimes under different reaction conditions like $\mathrm{pH}$ etc. Details and the mechanics of constructing Frost diagrams can be found in numerous basic chemistry books [1-17].

According to a rigorous line of argument, predictions based on Frost diagrams are not more accurate than those given by only considering the standard potentials of couples. In other words, the predictions given by this strategy are only accurate when the redox species involved in the reaction are in their standard states. But these predictions may sometimes be inverted in other experimental conditions. Because standard potentials involve $\mathrm{pH} 0$, Frost diagrams are implicitly drawn for $\mathrm{pH}$ 0. For other $\mathrm{pH}$ values, the apparent standard potentials must be used in order to build the diagrams. Actually, they are often drawn for $\mathrm{pH} 0$ and $\mathrm{pH} 14$. Hitherto, the Frost diagrams can be used only under standard conditions, i.e. for semi-quantitative estimations. However, under non-standard, real conditions, a number of factors such as $\mathrm{pH}$, concentrations of soluble forms, participation of each valence state of element in diverse auxiliary chemical reactions (precipitation, complex formation, hydrolysis etc.) can exert influence on the disproportionation-comproportionation processes.

The Frost diagrams, easily realizable, clearly represent the processes of ion dismutation. But FD drawn this way, suffer from a number of drawbacks, namely:

- The diagrams can be only used under standard conditions. Under real conditions a decisive influence on the possibility of occurring dismutation processes can have such factors as acidity, concentration of soluble species and the formation of solid phases;

- In function of the solution $\mathrm{pH}$, metal ions are subject to hydrolysis with the formation of mononuclear and polynuclear hydroxocomplexes. In the second case the degree of disproportionation depends on the concentration of metal ions in the solution [18]; 
- Conditions of dismutation reactions may be influenced by complex formation reactions.

The goal of this paper is to propose a method to build Frost diagrams under real, non-standard conditions (called here as modified Frost diagrams, MFD), based on rigorous thermodynamic analysis of chemical equilibria in the system $\mathrm{Ru}-\mathrm{H}_{2} \mathrm{O}$, taken into consideration all the factors mentioned above. Proof of the theorem for necessary conditions of disproportionation processes has been also completed.

\section{Theory and calculations}

\section{Proof of the theorem for necessary conditions of disproportionation processes}

The disproportionation occurs if the value $\Delta \tilde{G}_{f}^{0}(i)$ of the analyzed ion is situated above the straight line joining the points $\Delta \tilde{G}_{f}^{0}(i)$ of neighboring valence forms on the $\Delta \tilde{G}_{f}^{0}(i)=f(n)$ diagram. In the case of oxygen-containing species (ions, molecules), on the ordinate axis the standard Gibbs free energy of formation of ion $\left(\Delta G_{f}^{0}(i)\right)$ minus the Gibbs energy of a number $x$ of water molecules, equal to the number of oxygen atoms in the examined species $\left(\Delta G_{f}^{0^{*}}=\Delta G_{f}^{0}-x \Delta G_{f}^{0}\left(\mathrm{H}_{2} \mathrm{O}\right)\right)$ is placed. When the valence form contains more than one element, which is subject to redox transformations, the $\Delta G_{f}^{0^{*}}$ values is calculated per one atom. The standard redox potential represents the negative slope of the straight line joining two points on the diagram, corresponding to any two valence forms, since the equality is valid:

$$
E^{0}=-\Delta G_{f}^{0 *} / n
$$

Here the $n$ quantity coincides with the degree of oxidation of the ion of interest. The angle of inclination of the curve for the given pair of the valence forms characterizes the ability of interaction with the formation of the products with a lower Gibbs energy. By means of this diagram is easy to establish whether a particular ion is stable against disproportionation. The disproportionation occurs when $\Delta G_{f}^{0^{*}}$ of ion lies above the straight line joining the Gibbs energies of two neighboring valence forms. This is explained by the fact that $\Delta G_{f}^{0^{*}}$ of the products of disproportionation reaction corresponds to the point situated at the intersection of this line with the vertical passing through the point corresponding to this ion. In addition, the greater the gain in energy, the less stable the ion towards its disproportionation in solution. This property of diagram can be fundamented using thermodynamic and linear algebra methods. We present here a brief proof.

We will examine the redox system formed from the ions of an element, which are in three valence states: $a, b$ and $c$. Let the following reaction of disproportionation takes place in this system:

$$
(c-a) M^{b+}=(c-b) M^{a+}+(b-a) M^{c+}
$$

and

$$
\Delta G_{r}^{0}=\left[(\mathrm{c}-\mathrm{b}) \Delta G_{\mathrm{f}}^{0}(\mathrm{a})+(\mathrm{b}-\mathrm{a}) \Delta G_{\mathrm{f}}^{0}(\mathrm{c})\right]-(\mathrm{c}-\mathrm{a}) \Delta G_{\mathrm{f}}^{0}(\mathrm{~b})<0
$$

The reaction (1) is characterized by the following sequence of the standard redox potentials:

$$
E_{\mathrm{a} / \mathrm{b}}^{0}>E_{\mathrm{a} / \mathrm{c}}^{0}>E_{\mathrm{b} / \mathrm{c}}^{0}
$$

In the case of reaction (1) occurring, the points $\boldsymbol{a}\left(\Delta G_{f}^{0}(a), a\right), \boldsymbol{b}\left(\Delta G_{f}^{0}(b), b\right)$ and $\boldsymbol{c}\left(\Delta G_{f}^{0}(c), c\right)$ on the diagram $\Delta G_{f}^{0}(i)=f(n)$ correspond to the subsequent valence states (Fig. 1). 


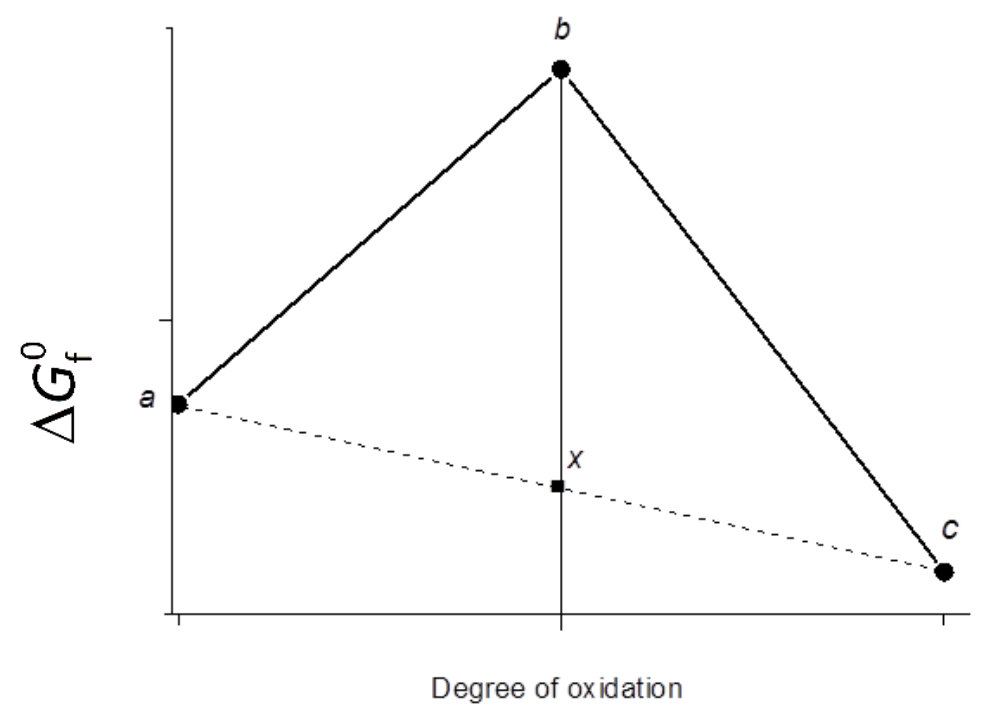

Figure 1. The Frost diagram for the case analyzed in this paper.

We will prove that if the point $\boldsymbol{b}\left(\Delta G_{f}^{0}(b), b\right)$, corresponding to the intermediate valence, lies above the straight line $\boldsymbol{a c}$ joining the $\boldsymbol{a}$ and $\boldsymbol{c}$ points, which characterize respectively the forms with lower and larger valences, then the disproportionation reaction (1) occurs. If the straight line $a c$ is drawn through the points $\boldsymbol{a}$ and $\boldsymbol{c}$, then the point $\boldsymbol{b}$ is situated above the line. We will draw the line perpendicular to the axis $n$ through the point $\boldsymbol{b}$. We will denote the intersection point of the straight line perpendicular to straight line ac through $x\left(\Delta G_{f}^{0}(x), x\right)$. The equation of the straight line can be represented by the expression

$$
\frac{\Delta G_{f}^{0}(x)-\Delta G_{f}^{0}(a)}{x-b}=\frac{\Delta G_{f}^{0}(c)-\Delta G_{f}^{0}(a)}{c-b}
$$

from where we get

$$
(c-x) \Delta G_{f}^{0}(a)+(x-a) \Delta G_{f}^{0}(c)=(c-a) \Delta G_{f}^{0}(x)
$$

On the other hand, under the conditions needed for the reaction (1) to occur, from the inequality (2) it follows that

$$
(c-b) \Delta G_{f}^{0}(a)+(b-a) \Delta G_{f}^{0}(c)<(c-a) \Delta G_{f}^{0}(b)
$$

Therefore, if the $\boldsymbol{b}$ point is located right above the $\boldsymbol{a c}$ straight line, the spontaneous disproportionation of $\mathrm{M}^{\mathrm{b+}}$ to $\mathrm{M}^{\mathrm{a}+}$ and $\mathrm{M}^{\mathrm{ct}}$ takes place. So, the proof is done!

Thermodynamic analysis of disproportionation - comproportionation conditions of Ru in different valence states

Fig. 2 shows the disproportionation of $\mathrm{Ru}(\mathrm{II})$ in $\mathrm{Ru}(0)$ and $\mathrm{Ru}(\mathrm{III})$.

The dotted line drawn through the points corresponding to $\mathrm{Ru}(0)$ and $\mathrm{Ru}(\mathrm{III})$ is well below the corresponding $\Delta G_{f}^{0}$ point of the $\mathrm{Ru}(\mathrm{II})$ ion. Similarly, one deduces that species $\mathrm{Ru}(\mathrm{V}), \mathrm{Ru}(\mathrm{VI})$ and $\mathrm{Ru}(\mathrm{VII})$ are unstable with respect to disproportionation in $\mathrm{Ru}(\mathrm{IV})$ andRu (VII). For example, at disproportionation of $\mathrm{Ru}(\mathrm{VI}), \Delta G_{\mathrm{f}}^{0}$ comes down to the value corresponding to the cross point on the dotted line. Therefore, the disproportionation of $\mathrm{Ru}(\mathrm{VI})$ to $\mathrm{Ru}(\mathrm{IV})$ and $\mathrm{Ru}(\mathrm{VIII})$ is accompanied by the $\Delta G_{f}^{0}$ decrease and, as a result, it occurs spontaneously. Higher is the energy gain, the more 
unstable is ion with respect to disproportionation in solution. But, as it was above-mentioned, FD drawn by this way, suffers from a number of weaknesses. The improved version of the Frost diagrams under conditions, different from standard ones, MFD, enables to use the Gibbs energy change of oxidation half reaction of metal to the corresponding valence state under real conditions instead of $\Delta G_{f}^{0}$.

For example, in the case of Ru(IV) the change in standard Gibbs energy of half reaction:

$$
\mathrm{Ru}+2 \mathrm{H}_{2} \mathrm{O}=\mathrm{Ru}(\mathrm{OH})_{2}^{2+}+2 \mathrm{H}^{+}+4 \mathrm{e}
$$

is equal to

$$
\Delta G_{r}^{0}=\Delta G_{f}^{0}\left(\mathrm{Ru}(\mathrm{OH})_{2}^{2+}\right)-2 \Delta G_{\mathrm{f}}^{0}\left(\mathrm{H}_{2} \mathrm{O}\right)=\Delta G_{\mathrm{f}}^{0}\left(\mathrm{Ru}(\mathrm{OH})_{2}^{2+}\right)
$$

For the calculation of the change in standard Gibbs energy of half reaction (6) under real conditions the equation of isotherm reaction should be applied:

$$
\Delta G_{\mathrm{r}}=\Delta G_{\mathrm{r}}^{0}+v \log C_{\mathrm{Ru}}^{0}\left[\mathrm{H}^{+}\right]^{4},
$$

where $v=R T / F \ln 10, C_{\mathrm{Ru}}^{0}$ is the ruthenium total concentration in mixture. Within the used approach of MFD, the slope of the line that connects two valence states, constitutes the formal (conditional) redox potential. In the case of formation of the solid phase, $\mathrm{RuO}_{2} \cdot \mathrm{H}_{2} \mathrm{O}(\mathrm{s})$ according to the equation of reaction

$$
\mathrm{Ru}+4 \mathrm{H}_{2} \mathrm{O}=\mathrm{RuO}_{2} \times 2 \mathrm{H}_{2} \mathrm{O}(\mathrm{s})+4 \mathrm{H}^{+}+4 \mathrm{e},
$$

the equation of isotherm is

$$
\Delta G_{r}=\Delta G_{r}^{0}+v \log \left[\mathrm{H}^{+}\right]^{4}=\Delta G_{r}^{0}+4 v p H
$$

\section{Results and discussion}

A preliminary step in the construction of MFD is to determine the thermodynamic stability of valence states, in function on the $\mathrm{pH}$ solution and $C_{\mathrm{Ru}}^{0}$ [19] (see Table 1).

Table 1. Calculation of the MFD for $\mathrm{Ru}-\mathrm{H}_{2} \mathrm{O}$ at different $\mathrm{pH}$ values

\begin{tabular}{ccc|ccc}
\hline $\mathbf{R u}$ (II) & $\mathrm{Ru}^{2+}$ & $0<\mathrm{pH}<14.0$ & $\mathbf{R u}(\mathrm{V})$ & $\mathrm{Ru}_{2} \mathrm{O}_{5}(\mathrm{am})$ & $0<\mathrm{pH}<14.0$ \\
$\mathbf{R u}(\mathrm{III})$ & $\mathrm{Ru}^{3+}$ & $0<\mathrm{pH}<1.76$ & $\mathbf{R u}(\mathrm{VI})$ & $\mathrm{RuO}_{4}^{2-}$ & $0<\mathrm{pH}<14.0$ \\
& $\mathrm{Ru}(\mathrm{OH})_{2}^{+}$ & $1.76<\mathrm{pH}<2.12$ & $\mathbf{R u}(\mathrm{VII})$ & $\mathrm{RuO}_{4}^{-}$ & $0<\mathrm{pH}<14.0$ \\
& $\mathrm{Ru}(\mathrm{OH})_{3}(\mathrm{am})$ & $2.12<\mathrm{pH}<14.0$ & $\mathrm{Ru}(\mathrm{VIII})$ & $\mathrm{H}_{2} \mathrm{RuO}_{5}$ & $0<\mathrm{pH}<11.53$ \\
& $\mathrm{H}_{2} \mathrm{O}$ & & & & $11.5<\mathrm{pH}<$ \\
$\mathbf{R u}(\mathrm{IV})$ & $\mathrm{Ru}(\mathrm{OH})_{2}^{2+}$ & $0<\mathrm{pH}<1.05$ & & $\mathrm{HRuO}_{5}^{-}$ & 14.0 \\
& $\mathrm{Ru}_{4}(\mathrm{OH})_{12}^{4+}$ & $1.05<\mathrm{pH}<3.93$ & & & \\
& $\mathrm{RuO}_{2} \cdot \mathrm{H}_{2} \mathrm{O}(\mathrm{s})$ & $3.93<\mathrm{pH}<14.0$ & & & \\
\hline
\end{tabular}

Then, the change in Gibbs energy for the respective reactions is calculated. For example, at $\mathrm{pH}$ 13, we get

1. $\operatorname{Ru}(0): \Delta G_{\mathrm{r}}^{0}=0 \mathrm{eV}$ 
2. $R u(I I): R u=R u^{2+}+2 e, \Delta G_{r}^{0}=1.558 \mathrm{eV}$

$$
\Delta G_{\mathrm{r}}=\Delta G_{\mathrm{r}}^{0}+v \log C_{\mathrm{Ru}}^{0}=1.321 \mathrm{eV}
$$

3. $\mathrm{Ru}(\mathrm{III}): \mathrm{Ru}+4 \mathrm{H}_{2} \mathrm{O}=\mathrm{Ru}(\mathrm{OH})_{3} \times \mathrm{H}_{2} \mathrm{O}(\mathrm{am})+3 \mathrm{H}^{+}+3 \mathrm{e}, \Delta G_{\mathrm{r}}^{0}=1.894 \mathrm{eV}$

$$
\Delta G_{\mathrm{r}}=\Delta G_{\mathrm{r}}^{0}-3 v \mathrm{pH}=-0.413 \mathrm{eV}
$$

4. $\mathrm{Ru}(\mathrm{IV}): \mathrm{Ru}+4 \mathrm{H}_{2} \mathrm{O}=\mathrm{RuO}_{2} \times 2 \mathrm{H}_{2} \mathrm{O}(\mathrm{s})+4 \mathrm{H}^{+}+4 \mathrm{e}, \Delta \mathrm{G}_{\mathrm{r}}^{0}=2.671 \mathrm{eV}$

$$
\Delta G_{r}=\Delta G_{r}^{0}-4 v p H=-0.405 e V
$$

5. $\mathrm{Ru}(\mathrm{V}): \mathrm{Ru}+5 / 2 \mathrm{H}_{2} \mathrm{O}=1 / 2 \mathrm{Ru}_{2} \mathrm{O}_{5}(\mathrm{am})+5 \mathrm{H}^{+}+5 \mathrm{e}, \Delta G_{\mathrm{r}}^{0}=3.840 \mathrm{eV}$

$$
\Delta G_{r}=\Delta G_{r}^{0}-5 v p H=-0.005 e V
$$

6. $\mathrm{Ru}(\mathrm{VI}): \mathrm{Ru}+4 \mathrm{H}_{2} \mathrm{O}=\mathrm{RuO}_{4}^{2-}+8 \mathrm{H}^{+}+6 \mathrm{e}, \Delta \mathrm{G}_{\mathrm{r}}^{0}=6.655 \mathrm{eV}$

$$
\Delta G_{\mathrm{r}}=\Delta G_{\mathrm{r}}^{0}+v \log C_{\mathrm{Ru}}^{0}-8 v \mathrm{pH}=0.266 \mathrm{eV}
$$

7. $\mathrm{Ru}(\mathrm{VII}): \mathrm{Ru}+4 \mathrm{H}_{2} \mathrm{O}=\mathrm{RuO}_{4}^{-}+8 \mathrm{H}^{+}+7 \mathrm{e}, \Delta G_{\mathrm{r}}^{0}=7.241 \mathrm{eV}$

$$
\Delta G_{\mathrm{r}}=\Delta G_{\mathrm{r}}^{0}+v \log C_{\mathrm{Ru}}^{0}-8 v \mathrm{pH}=0.852 \mathrm{eV}
$$

8. $\mathrm{Ru}(\mathrm{VIII}): \mathrm{Ru}+5 \mathrm{H}_{2} \mathrm{O}=\mathrm{HRuO}_{5}^{-}+9 \mathrm{H}^{+}+8 \mathrm{e}, \Delta G_{\mathrm{r}}^{0}=8.919 \mathrm{eV}$

$$
\Delta G_{\mathrm{r}}=\Delta G_{\mathrm{r}}^{0}+v \log C_{\mathrm{Ru}}^{0}-9 v \mathrm{pH}=1.761 \mathrm{eV}
$$

MFD for $C_{\mathrm{Ru}}^{0}=10^{-4}$ and $10^{-6} \mathrm{~mol} / \mathrm{L}$ at different $\mathrm{pH}$ values are presented on Figs. 2 and 3. In all the cases MFD suffer essential changes with $\mathrm{pH}$ variation. On this base the following conclusions can be made:

1. In acidic medium ( $\mathrm{pH}=0$ and 1 ) stable valence states are: for $\mathrm{Ru}(\mathrm{III})\left(\mathrm{Ru}^{3+}\right.$ and $\left.\mathrm{Ru}(\mathrm{OH})_{2}^{+}\right), \mathrm{Ru}(\mathrm{IV})$ $\left(\mathrm{Ru}(\mathrm{OH})_{2}^{2+}\right.$ or $\left.\mathrm{Ru}_{4}(\mathrm{OH})_{12}^{4+}\right)$ and $\mathrm{Ru}(\mathrm{VIII})\left(\right.$ as $\left.\mathrm{H}_{2} \mathrm{RuO}_{5}\right)$.

2. $\mathrm{Ru}(\mathrm{II})$ disproportionates according to the equations:

$3 R u^{2+}=R u+2 R u^{3+}$

$3 \mathrm{Ru}^{2+}+4 \mathrm{H}_{2} \mathrm{O}=\mathrm{Ru}+2 \mathrm{Ru}(\mathrm{OH})_{2}^{+}+4 \mathrm{H}^{+}$.

3. $\mathrm{Ru}(\mathrm{V})$ at $\mathrm{pH}=\mathrm{O}$ and $\mathrm{pH}=1$ disproportionates according to the scheme

$2 \mathrm{Ru}_{2} \mathrm{O}_{5}(\mathrm{am})+\mathrm{H}_{2} \mathrm{O}+6 \mathrm{H}^{+}=3 \mathrm{Ru}(\mathrm{OH})_{2}^{2+}+\mathrm{H}_{2} \mathrm{RuO}_{5}(\mathrm{aq})$

At the same $\mathrm{pH}$ values, $\mathrm{Ru}(\mathrm{VI})$ and $\mathrm{Ru}(\mathrm{VII})$ are instable:

$$
\begin{array}{ll}
2 \mathrm{RuO}_{4}^{2-}+6 \mathrm{H}^{+}=\mathrm{H}_{2} \mathrm{RuO}_{5}+\mathrm{Ru}(\mathrm{OH})_{2}^{2+}+\mathrm{H}_{2} \mathrm{O} & (\mathrm{pH} 1) \\
2 \mathrm{RuO}_{4}^{2-}+5 \mathrm{H}^{+}=\mathrm{H}_{2} \mathrm{RuO}_{5}+1 / 4 \mathrm{Ru}_{4}(\mathrm{OH})_{12}^{4+} & (\mathrm{pH} 3) \\
4 \mathrm{RuO}_{4}^{-}+\mathrm{H}_{2} \mathrm{O}+6 \mathrm{H}^{+}=3 \mathrm{H}_{2} \mathrm{RuO}_{5}+\mathrm{Ru}(\mathrm{OH})_{2}^{2+} & (\mathrm{pH} 1) \\
4 \mathrm{RuO}_{4}^{-}+2 \mathrm{H}_{2} \mathrm{O}+5 \mathrm{H}^{+}=3 \mathrm{H}_{2} \mathrm{RuO}_{5}+1 / 4 \mathrm{Ru}_{4}(\mathrm{OH})_{12}^{4+} & (\mathrm{pH} 3)
\end{array}
$$

The diagrams $\Delta G_{r}(n)$ can also be used in the presence of complexing agent:

$$
\begin{array}{ll}
\mathrm{Ru}(\mathrm{IV}): \mathrm{Ru}(\mathrm{OH})_{2}^{2+}+\mathrm{nCl}^{-}=\mathrm{Ru}(\mathrm{OH})_{2} \mathrm{Cl}_{n}^{2-\mathrm{n}}, & \mathrm{n}=0-5, \\
\mathrm{Ru}(\mathrm{III}): \mathrm{Ru}^{3+}+\mathrm{nCl}^{-}=\mathrm{RuCl}_{\mathrm{n}}^{3-\mathrm{n}}, & \mathrm{n}=0-6, \\
\mathrm{Ru}(\mathrm{II}): \mathrm{Ru}^{2+}+\mathrm{Cl}^{-}=\mathrm{RuCl}^{+} . &
\end{array}
$$


In this case $\Delta G_{\mathrm{r}}$ is a function of 3 variables: $C_{\mathrm{Ru}}^{0}, C_{\mathrm{Cl}}^{0}$ and $\mathrm{pH}$. For the construction of diagrams $\Delta G_{\mathrm{r}}=f(n)$ at different $C_{\mathrm{Cl}}^{0}$, it is necessary to maintain constant other two parameters $-\mathrm{pH}$ and $C_{\mathrm{Ru}}^{0}$.

The distribution of different species of $\mathrm{Ru}(\mathrm{IV}), \mathrm{Ru}(\mathrm{III})$ and $\mathrm{Ru}(\mathrm{II})$ in function on $\log \left[\mathrm{Cl}^{-}\right](\mathrm{pH}=0$, $C_{\mathrm{Ru}}^{0}=10^{-6} \mathrm{~mol} / \mathrm{L}$ ) is the following:

\begin{tabular}{llll}
\hline $\mathrm{Ru}(\mathrm{III})$ & \multicolumn{3}{l}{$\mathrm{Ru}(\mathrm{IV})$} \\
\hline $\mathrm{Ru}^{3+} \log \left[\mathrm{Cl}^{-}\right]<-2.17$ & $\mathrm{Ru}(\mathrm{OH})_{2}^{2+}$ & $\log \left[\mathrm{Cl}^{-}\right]<-1.39$ \\
$\mathrm{RuCl}^{2+}$ & $-2.17<\log \left[\mathrm{Cl}^{-}\right]<-1.57$ & $\mathrm{Ru}(\mathrm{OH})_{2} \mathrm{Cl}^{+}$ & $-1.39<\log \left[\mathrm{Cl}^{-}\right]<-0.44$ \\
$\mathrm{RuCl}_{2}^{+}$ & $-1.57<\log \left[\mathrm{Cl}^{-}\right]<-0.54$ & $\mathrm{Ru}(\mathrm{OH})_{2} \mathrm{Cl}_{4}^{2-}$ & $\log \left[\mathrm{Cl}^{-}\right]>-0.44$ \\
$\mathrm{RuCl}_{3}^{0}$ & $-0.54<\log \left[\mathrm{Cl}^{-}\right]<0.16$ & $\mathrm{Ru}(\mathrm{II})$ & \\
$\mathrm{RuCl}_{4}^{-}$ & $0.16<\log \left[\mathrm{Cl}^{-}\right]<0.30$ & $\mathrm{Ru}^{2+}$ & $\log \left[\mathrm{Cl}^{-}\right]<0.48$ \\
$\mathrm{RuCl}_{5}^{2-}$ & $0.30<\log \left[\mathrm{Cl}^{-}\right]<0.40$ & $\mathrm{RuCl}^{+}$ & $\log \left[\mathrm{Cl}^{-}\right]>0.48$ \\
$\mathrm{RuCl}_{6}^{3-}$ & $\log \left[\mathrm{Cl}^{-}\right]>0.40$ & & \\
\hline
\end{tabular}

The diagram $\Delta G_{\mathrm{r}}(\mathrm{n})$ for different $C_{\mathrm{Cl}}^{0}\left(C_{\mathrm{Cl}}^{0}>C_{\mathrm{Ru}}^{0}\right.$, thus $\left.C_{\mathrm{Cl}}^{0}=\left[\mathrm{Cl}^{-}\right]\right)$is shown in Fig.4.

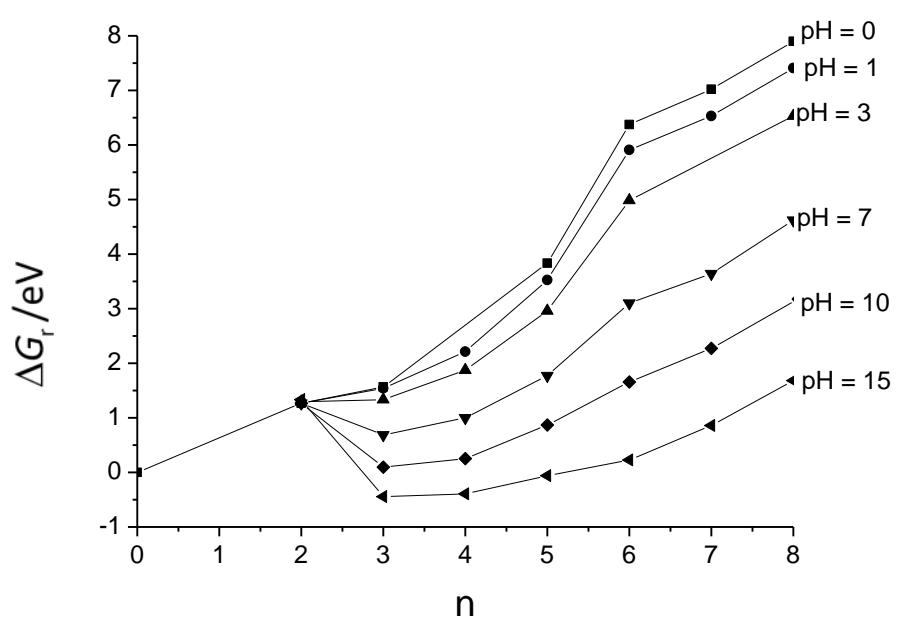

Figure 2. Modified Frost diagrams for the system $\mathrm{Ru}-\mathrm{H}_{2} \mathrm{O}, \mathrm{C}_{\mathrm{Ru}}^{0}=10^{-4} \mathrm{~mol} / \mathrm{L}$

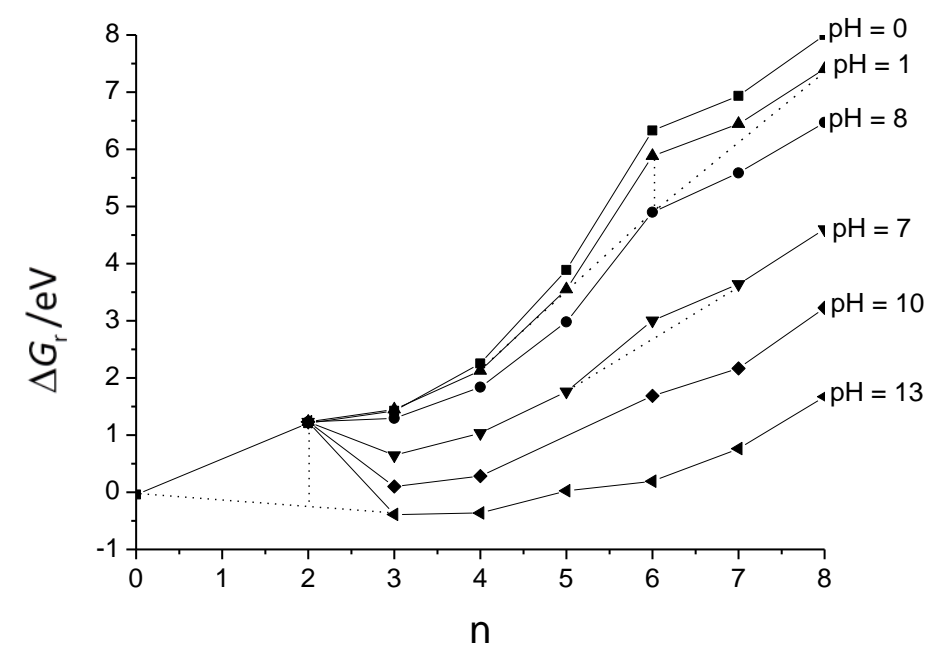

Figure 3. Change in Gibbs energy of the half reaction of oxidation of metallic Ru to respective valence state versus degree of oxidation (n) for the system $\mathrm{Ru}-\mathrm{H}_{2} \mathrm{O}, \mathrm{C}_{\mathrm{Ru}}^{0}=10^{-4} \mathrm{~mol} / \mathrm{L}$ 


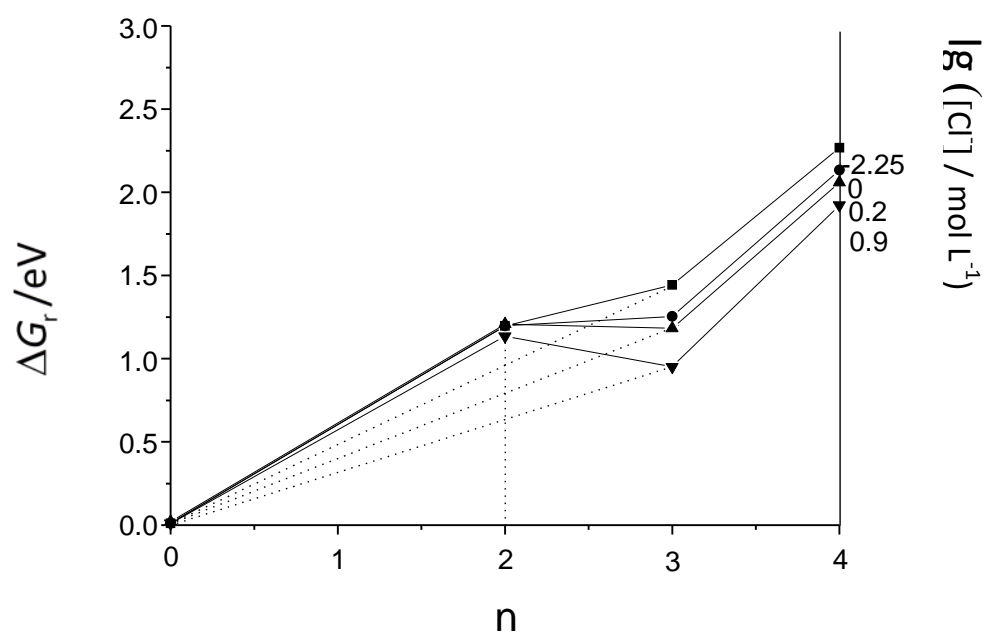

Figure 4. The diagram $\Delta G_{r}(n)$ for the system $\mathrm{Ru}-\mathrm{Cl}^{-}-\mathrm{H}_{2} \mathrm{O}, \mathrm{C}_{\mathrm{Ru}}^{0}=10^{-6} \mathrm{~mol} / \mathrm{L}$

\section{Conclusions}

1. The development of Frost diagrams for the soluble and insoluble species of ruthenium has been performed. An essential point in the modified method is that instead of the standard Gibbs energy of formation of ions $\Delta \tilde{G}_{f}^{0}(i)$, the use of the Gibbs energy change of the oxidation half reaction of element up to the respective valence state under non-standard conditions has been introduced.

2. A new type of diagrams for ruthenium species, based on the thermodynamic examination of the stability of solid phases and original conditions of mass balance in the heterogeneous systems, has been developed. The conditions of mass balance take into consideration all the chemical forms present in aqueous and solid phases, including inorganic and organic mononuclear and polynuclear forms.

3. Within the developed approach, the effect of major factors influencing on the distribution and concentration of soluble and insoluble species of key components in heterogeneous systems can be analyzed. The developed method of presentation of Frost diagrams removes the previous shortcomings and allows rapid and quantitative problem solving on the possibility of disproportionation of ions in real, non-standard conditions.

\section{References}

[1] D. Shriver, P. Atkins, C. Langford, Inorganic Chemistry, Oxford University Press, Oxford, UK, 1994.

[2] J. Warren, T. Tronic, J. Mayer, Chemical reviews 110 (2010) 6961-7001.

[3] J. M. Martinez de llarduya, F. Villafane, J. Chem. Ed. 71 (1994) 480.

[4] A. Michałowska-Kaczmarczyk, A. Asuero, M. Toporek, T. Michałowski, Critical Reviews in Analytical Chemistry 45 (2015) 241-269.

[5] W. Koppenol, D. Stanbury, P. Bounds, Free Radical Biology and Medicine 49 (2010) 317322.

[6] F. Armstrong, J. Hirst, Proceedings of the National Academy of Sciences 108 (2011) 1404914054.

[7] J. Burgot, Ionic Equilibria in Analytical Chemistry, Springer, New York, USA, 2012, p. 247263.

[8] A. Michałowska-Kaczmarczyk, M. Toporek, T. Michałowski, Electrochimica Acta 155 (2015) 217-227. 
[9] H. Eggenkamp, The Geochemistry of Stable Chlorine and Bromine Isotopes, Springer, Berlin Heidelberg, Germany, 2014, p. 21.

[10] J. Schneider, H. Jia, J. Muckerman, E. Fujita, Chemical Society Reviews 41 (2012) 2036-2051.

[11] J. Ibanez, M. Hernandez-Esparza, C. Doria-Serrano, A. Fregoso-Infante, M. Singh, Environmental Chemistry: Fundamentals, Springer Science \& Business Media, New York, USA, 2010.

[12] S. Chung, K. Chun, N. Kim, S. Jeong, H. Sim, J. Lee, H. Maeng, Match-Communications in Mathematical and in Computer Chemistry 72 (2014) 389-402.

[13] J. Muckerman et al., Inorganic Chemistry 53 (2014) 6904-6913.

[14] A. Lodge, M. Lacey, M. Fitt, N. Garcia-Araez, J. Owen, Electrochimica Acta 140 (2014) 168173.

[15] L. Wang, Y. Hung, N. Shammas, Physicochemical Treatment Processes, Humana Press, New Jork, USA, 2005.

[16] J. Kostera, J. McGarry, A. Pacheco, Biochemistry 49 (2010) 8546-8553.

[17] D. Smith, Journal of Chemical Education 73 (1996) 1099.

[18] I. Povar, Bulletin of Academy of Sciences of the MSSR, Series of Biological and chemical Sciences, 5 (1993) 64-67.

[19] I. Povar, O. Spînu, Journal of Electrochemical Science and Engineering (2016) doi: $10.5599 /$ jese.226

(c) 2016 by the authors; licensee IAPC, Zagreb, Croatia. This article is an open-access article distributed under the terms and conditions of the Creative Commons Attribution license (http://creativecommons.org/licenses/by/4.0/) 